\title{
A Survey of Tracheostomy Care in Kuwait: Are Nurses Adequately Informed?
}

\author{
Khaled Alajmi ${ }^{1 *}$, Imtiaz M Qazi ${ }^{*}$, Marwan Alqunaee ${ }^{2}$, Zakir Hussain ${ }^{3}$ and Sarah I Qazi ${ }^{4}$ \\ ${ }^{1}$ Department of Otorhinolaryngology, Head and Neck Surgery, Farwaniya Hospital, Kuwait \\ ${ }^{2}$ Department of Otorhinolaryngology, Head and Neck Surgery, Kuwait Institute of Medical Specialisation, Kuwait \\ ${ }^{3}$ Department of Otorhinolaryngology, Head and Neck Surgery, Zain Hospital, Kuwait \\ ${ }^{4}$ Sinhgad Dental College, India
}

Submission: April 19, 2021; Published: May 13, 2021

*Corresponding author: Khaled Alajmi and Imtiaz M Qazi, Department of Otorhinolaryngology, Head and Neck Surgery, Farwaniya Hospital, Kuwait

\section{Abstract}

Introduction: Tracheostomy is a common surgical procedure with specific indications. The complications patients with a tracheostomy suffer from depends greatly on the post-operative care they receive. In Kuwait, this is provided by the nursing staff. Therefore, we aim to evaluate their knowledge in providing care for patients with a tracheostomy.

Methods: Following extensive literature review, a questionnaire consisting of six questions covering main aspects of tracheostomy care was constructed; this was distributed among three major hospitals targeting the nursing staff. The nurses were asked to answer with a 'yes' or 'no' only. The participants were divided into staff nurses (who are responsible for patients in their respective allocated wards) and senior nurses (head nurse of the ward) and results from each group were quantified and processed. Graphical representation of the results was also created.

Results: 239 (96\%) out of 270 of the nursing staff responded to the questionnaire. There were 19 senior nurses and 239 staff nurses. The participant was asked six questions assessing their knowledge of main principles in the management of tracheostomy tube. Most of the staff nurses answered 'no' to the questions asked whereas the contrary was true for the senior nurses where most answered with 'yes'.

Conclusion: In view of this lack of knowledge amongst most nursing staff, evidence-based guidelines should be implemented accompanied by advanced training of the staff to improve the care provided to patients with tracheostomy tubes.

Keywords: Tracheostomy care guidelines; Tracheostomy care; Tracheostomy complications; Staff nurses; Senior nurses

Objective

A questionnaire-based survey was conducted to evaluate the current practice of tracheostomy care by nurses in hospital wards, intensive care, and coronary care units of various hospitals in Kuwait, along with the possibility of implementing current international standards of tracheostomy care as a means of improving overall care and reducing the rate of complications.

\section{Introduction}

Tracheostomy is a common surgical procedure performed by creating an opening in the cervical trachea followed by the insertion of a cuffed or an uncuffed tube. Indications for Tracheostomy can be generalized under four categories. Firstly, in patients who suffer from upper airway obstruction. Secondly, in those who have an advanced lung disease. Tracheostomy is also indicated in patients who require prolonged artificial ventilation and lastly, in patients with impaired swallowing ability and reduced cough reflex to protect the airway from aspiration [1]. The procedure does not come without risks, however. Morris ET. Al. divided Tracheostomy risks into emergencies and complications. Emergencies include hemorrhage, tube dislodgement with loss of airway and tube obstruction. Whereas the complications that could occur are infection, bleeding, tracheomalacia, skin breakdown, tracheainnominate and tracheoesophageal fistula [2].

Inadequate or inappropriate tracheostomy care is strongly associated with an increased mortality and morbidity [3]. Therefore, focusing on the care of the tracheostomy is the key to preventing many complications.

With the absence of guidelines and dedicated tracheostomy care teams, there is a national concern regarding tracheostomy 
care. In the wards of hospitals around Kuwait, it is the nursing staff who usually provide care for patients with tracheostomy. Thus, nursing staff knowledge of the appropriate method of care and of the parameters that are directly associated with complications is deemed imperative.

Advances in the healthcare in Kuwait along with improvements in the delivery of treatment have resulted in an increased number of patients who survive critical conditions. Furthermore, locally, road traffic accidents are a major source of morbidity and mortality among the local population. According to recent statistics published by the General Department of Traffic of the Ministry of Interior in Kuwait; in the year 2012, Kuwait, with a population of 3.5 million, had 86,542 RTAs resulting in 454 fatalities and 9,959 injuries of which 4,892 were critical [4]. Consequently, the number of patients with irreversible brain injury on ventilator support who require tracheostomy is on the rise. Motivated by the lack of clear local guidelines and the need for reform, we carried out a survey assessing the skills and knowledge of the nursing staff in the management and care of patients with a tracheostomy. To the best of our knowledge, this study is the first in addressing this issue.

\section{Methods}

The literature was extensively researched regarding the important components of tracheostomy care management to aid in the design of the questionnaire and subsequent data used in the discussion. We used CINAHL, Embase and Pubmed with search phrases including 'tracheostomy care', tracheostomy management' and 'tracheostomy care guidelines' the search was also supplemented by using Google scholar. An otolaryngology consultant and a senior specialist reviewed the questionnaire. The nursing staff were presented with the following questions in the questionnaire and asked to answer with a 'yes' or 'no' only. Regarding the care of the patient with a tracheostomy tube:

Do you know...

a. What is the ideal 'cuff pressure'?

b. Whether patients with a tracheostomy require 'humidification'?

c. How often should the 'cuff be deflated'?

d. How should 'suctioning' be performed?

e. When should the 'sutures be removed' after the procedure?

f. When should the first 'tube be changed'?

We surveyed the nursing staffs of three major hospitals in Kuwait, covering medical wards, intensive care units and coronary care units. Out of the total 270 nursing staff who were asked to participate, 239 staff nurses (who are responsible for patients in their respective allocated wards) and 19 senior nurses (head nurse of the ward) responded to the questionnaire. (Response rate: $96 \%$ ). All data was collected and analyzed anonymously. The data was then quantified and processed, MS excel ${ }^{\odot}$ spreadsheets were composed comparing results of staff nurses and senior nurses. This was followed with a graphical representation of the data.

\section{Results}

Table 1: Comparing the results from staff nurses (239) with the senior nurses (19).

\begin{tabular}{|c|c|c|}
\hline Cuff Pressure & Senior Nures \% & Staff Nurses (\%) \\
\hline Yes & $12(63)$ & 0 \\
\hline No & 7 (37) & $239(100)$ \\
\hline Total & 19 & 239 \\
\hline Cuff Deflation & Senior Nures \% & Staff Nurses (\%) \\
\hline Yes & $16(84)$ & $5(2)$ \\
\hline No & $3(16)$ & $234(98)$ \\
\hline Total & 19 & 239 \\
\hline Suctioning & Senior Nures \% & Staff Nurses (\%) \\
\hline Yes & $19(100)$ & $18(7)$ \\
\hline No & 0 & 221 (93) \\
\hline Total & 19 & 239 \\
\hline Humidification & Senior Nures \% & Staff Nurses (\%) \\
\hline Yes & $19(100)$ & $25(10)$ \\
\hline No & 0 & $214(90)$ \\
\hline Total & 19 & 239 \\
\hline
\end{tabular}




\section{Global Journal of Otolaryngology}

\begin{tabular}{|c|c|c|}
\hline Suture Removal & Senior Nures \% & Staff Nurses (\%) \\
\hline Yes & $19(100)$ & $231(97)$ \\
\hline No & 0 & $8(3)$ \\
\hline Total & 19 & 239 \\
\hline Tube Replacement & Senior Nures \% & Staff Nurses (\%) \\
\hline Yes & $15(79)$ & $13(5)$ \\
\hline No & $4(21)$ & $226(95)$ \\
\hline Total & 19 & 239 \\
\hline
\end{tabular}

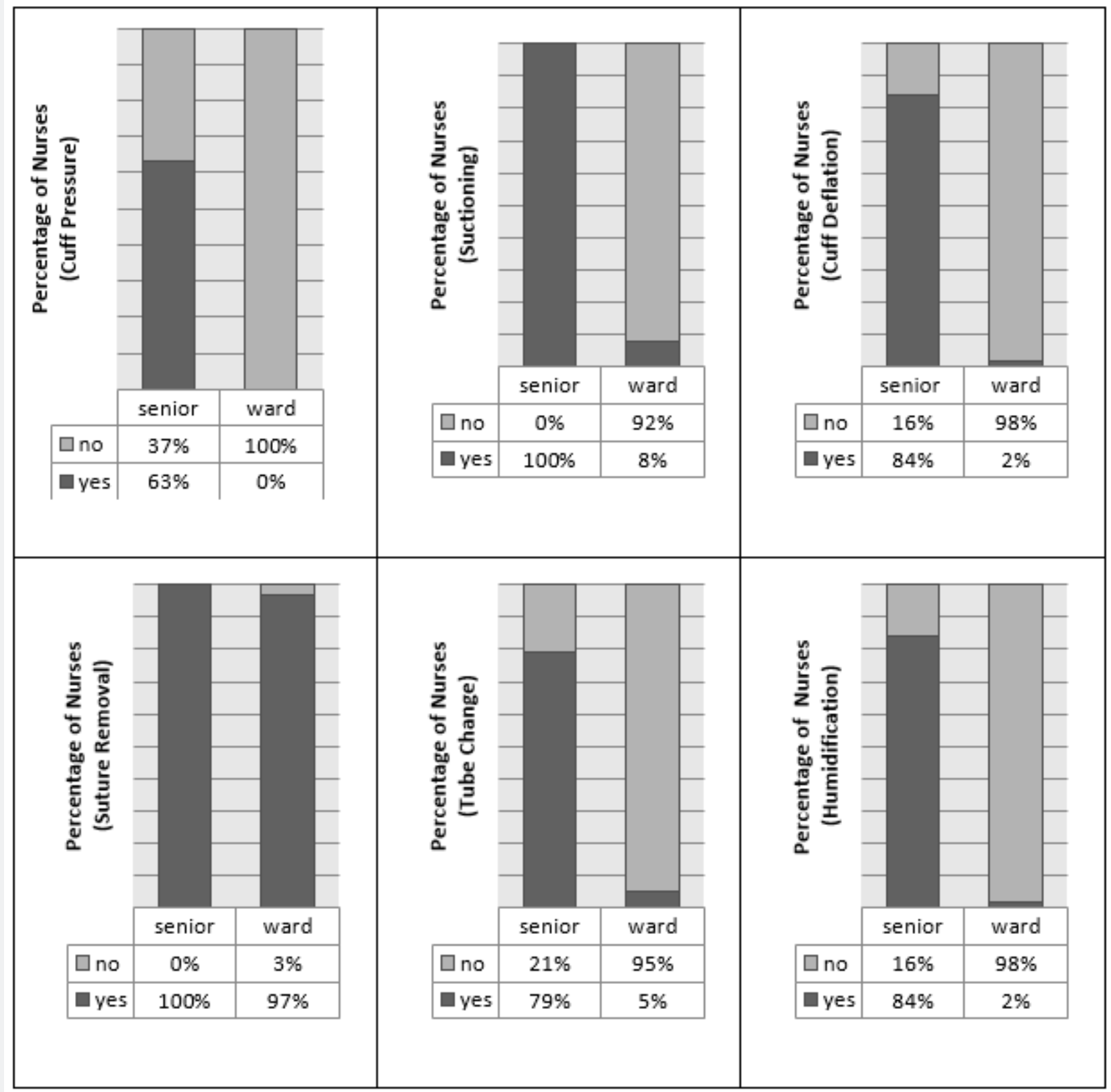

Figure 1: Comparing the results from staff nurses (239) with the senior nurses (19). 
The data were entered into a spreadsheet and two tables were constructed comparing the results from staff nurses (239) with the senior nurses (19). When asked about the ideal cuff pressure, $239(100 \%)$ out of the 239 staff nurses answered 'no', whereas 12 (63\%) out of the 19 senior nurses answered, 'yes' and 7 (37\%) answered 'no'. The staff nurses were also asked about their knowledge on humidification 214 (90\%) of them answered 'no' and $25(10 \%)$ answered 'yes', all of the senior nurses responded with 'yes', 19 (100\%). Further, the suctioning question revealed the following results: 221 (92\%) of the staff nurses responded with 'no' and 18 (8\%) responded with 'yes', however all of the senior nurses 19 (100\%) responded with 'yes'. Answers to questions of cuff deflation and tube change were also within similar ranges, $234(98 \%)$ of the staff nurses asked about cuff deflation answered with 'no' and only 5 (2\%) answered 'yes', however, 16 (84\%) senior nurses gave 'yes' as an answer and $3(16 \%)$ answered with 'no'. 225 (95\%) of the staff nurses answered, 'yes' when asked about their knowledge regarding tracheostomy tube change and 14 (5\%) answered 'no', whereas 14 (79\%) of senior nurses answered, 'yes' and 5 (21\%) answered 'no'. Finally, 231 (97\%) of the staff nurses when asked about stitch removal answered with 'yes', and 8 (3\%) answered 'no', on the other hand all senior nurses $19(100 \%)$ gave yes as an answer (Figure $1 \&$ Table).

The results clearly showed most of the staff nurses did not possess adequate knowledge required to provide the correct tracheostomy care to patients with regards to all the parameters, stitch removal being the only exception. The contrary is true for the senior nurses, where results revealed that they are competent in providing the correct tracheostomy care management in their wards, however, have not been able to pass this knowledge to the staff nurses.

\section{Discussion}

Several policies and guidelines exist in the literature with the aim of improving the care provided to patients with a tracheostomy [5-9]. In addition to general guidelines, some hospitals do have specific guidelines published by concerned departments like the otorhinolaryngology and nursing departments within the hospital. However, the lack of high-quality data makes it difficult to adopt a certain guideline and apply it. An evidence reviews by 'Garruba and Turner' in 2009 concluded that it was not possible identify any existing high-quality and evidence-based guidelines to support clinical practice in the management of tracheostomy patients [10]. However, they recommend few guidelines that address the management and care of patients with tracheostomy and even so advised that they should be read with caution [7-9].

\section{Cuff pressure and deflation}

Tracheostomy tubes are attached to cuffs, once inflated they serve the function of preventing gas leak and aspiration, especially in mechanically ventilated patients [11]. The cuff makes direct contact with the mucosa of the tracheal wall. Inflating the cuff pressure to above the range of 20-30 $\mathrm{mmHg}$ compromises the vascular perfusion of the tracheal mucosa and submucosa, consequently causing the well-documented complications: mucosa ciliary loss, ulceration, and bleeding. On the long term, tracheal stenosis and trachea-esophageal fistula might also develop [12]. Another challenge that mechanically ventilated patients with tracheostomy tube experience is the 'chasing the trachea phenomenon'. During inspiration, the airway pressure increases causing tracheal widening therefore a higher pressure and volume is required to seal the dilated airway, this is achieved by further inflating the cuff. However, during expiration, the trachea narrows around the highly inflated cuff causing stretching of the trachea. This results in a profound dilatation of the trachea on the long term.

Therefore, in an ideal setting, the cuff must be able to vary pressure according to the respiratory phase with the aid of a constant manometry device, partially inflated on inspiration and partially deflated on expiration. In a busy ward or ICU setting this is not readily available [13]. To avoid the compressive effects of the cuff on the mucosa some studies suggest deflating the cuff routinely, however, this has been proved to have a minimal effect on mucosal wall pressure and an increased risk of aspiration and hypoxemia. Nevertheless, cuff deflation is indicated in the following conditions: cuff leak evaluation, to clear the upper airway, or allow patient to vocalize [14]

Considering all the above-mentioned factors, the best management is that the cuff pressure should be kept between 15$20 \mathrm{mmHg}$ and a member of the nursing staff competent in using a manometry device should measure the pressure twice daily. This provides a high enough pressure to prevent aspiration and leakage, and low enough to prevent tracheal damage and removes the need for routine cuff deflation. However, when a manometry device is not available or the staff are not trained in using it, another option is to use tracheostomy tubes with high-volume low-pressure cuffs [7].

\section{Humidification and temperature}

Along many functions of the upper airway, filtering, heating, and humidifying the air remain the most significant. In patients with a tracheostomy these functions are lost and breathing dry and cold air results in cilia paralysis and crusting of secretions that in turn may result in many complications, which include infection and obstruction [15]. However, over humidification is also harmful as excess water vapour cools and loads in the tubing, this water reservoir might be a potential source of infection. The temperature of the humidified air should also be carefully measured and kept between $37^{\circ} \mathrm{C}$ and $40^{\circ} \mathrm{C}$, temperatures above $41^{\circ} \mathrm{C}$ causes mucosal damage [7]. Therefore, the assigned nursing staff should seek moderate humidification at a safe range of temperature. 


\section{Suctioning}

Having a tracheostomy prevents the patients increasing their intra-abdominal pressure sufficiently to cough and clear secretions; in addition, in the initial period of tracheostomy tube placement irritation to the mucosa occurs thus increasing the production of sputum [16]. As a result, tracheal suctioning is also one of the most important aspects in tracheostomy tube management, however many studies have identified associated risks with the procedure and some authors have recommended that suctioning is not to be routinely performed $[17,18]$. The risks and complications that may arise from suctioning include hypoxemia, cardiac arrhythmias, and trauma to the surrounding tissue as well as tube dislodgment. The development of such complications also depends on the length of the suctioning procedure as well as the type of the suctioning catheter [19].

Day et al. [20] reviewed the matter and went into further detailing recommendations at every step of the suctioning procedure, pre, during and post [20]. In view of this, we recommend that suctioning is only to be performed when the patients are unable to clear their secretions effectively. Prior to the procedure the patient should be hyper oxygenated, however, caution must be taken in COPD patients. The procedure must not take more than 10 seconds and is best performed with the use of small multi-eyed catheters at a suctioning pressure within 120-200 mmHg, high pressure causes tracheal damage and lower pressures may be ineffective in suctioning and prolongs the time of the procedure. Technically, suctioning should be made while withdrawing the catheter as this makes the procedure easier besides less damaging to the tracheal mucosa [7].

\section{Suture removal}

After performing a tracheostomy, the skin at the site of the incision is sutured. In addition, a tie may also be placed at each side of the tracheal wall and taped to the skin; this is to facilitate re-intubation in the case of tube dislodgment in the immediate postoperative period. The skin sutures should be removed on the $7^{\text {th }}$ post-operative day, along with the first tube replacement. This ensures an adequate time for the tract to mature and less chance of developing skin irritation from prolonged suture placement [21].

\section{Tube replacement}

Tracheostomy tube replacement is indicated for the following reasons. In the first week post tracheostomy and after the tract has matured the tube should be replaced. In addition, tube change is also routinely recommended every 3 months due to biofilm accumulation and compromise of the structure of the tube. Tube replacement is also required in case of any structural or functional malfunction such as: tube malposition, cuff leak or tube fracture [22].

\section{Study limitations}

We acknowledge some limitations in our study. The demographics of the nursing staff and the number of years each have in experience were not asked in the questionnaire, in addition, the results were analyzed collectively and differences such as hospital areas and ward specialties were not considered. This would have broadened our research perspective and help us identify better areas of focus and provide reforms. Furthermore, the ratio of senior staff (19) to staff nurses (239) is seen to contribute towards a statistically flawed interpretation when comparing percentages results. This can be justified by the fact the total number of senior nurses is much lower in the wards across all hospitals in Kuwait. Therefore, it would not have been possible to provide a more representative sample even if it were planned. Nevertheless, we hope that this study provides the basis for a further detailed research.

\section{Conclusion and Recommendations}

Results of this study revealed an alarming number of inadequately trained nursing staff when it comes to providing care of patients with a tracheostomy. Many steps should be taken to start a reform. To begin with, an intervention at the earliest stage in the selection criteria and recruitment process will have the greatest impact; allocating nurses who have experience in dealing with patients with a tracheostomy could improve outcomes. Secondly, providing regular workshops and seminars where the nursing staff receive up-to-date training, attendance could be encouraged by a reward system. Furthermore, the printout of current guidelines on tracheostomy and providing them in the wards will aid in the delivery of the best care. The availability of a multidisciplinary team consisting of a surgeon, respiratory therapist, speech, and language therapist besides a clinical nurse to follow and manage patients with a tracheostomy has been proven to reduce the rate of complications.

This can be applied especially in the absence of a formal guideline to ensure top evidence-based management from each respective specialty [23]. In review of the literature, we recommend the application of the Best Practice Statement: Caring for a Patient with a Tracheostomy published by the NHS quality improvement - Scotland, the guideline covers all aspects of tracheostomy care with clear steps on how to perform each of the procedures backed up by evidence-based data. Further studies are also required to detail the number of tracheostomy procedures performed and the rate of complications all around Kuwait, this must be followed by the application of an intervention and following up the impact of this on the rate of complications.

\section{References}

1. Russell C, Matta B (2004) Tracheostomy, A Multi-Professional Handbook. Cambridge University Press, UK. 
2. Morris LL, Whitmer A, Mcintosh E (2013) Tracheostomy care and complications in the intensive care unit. Crit Care Nurse 33(5): 18-30.

3. St john RE, Malen JF (2004) Contemporary issues in adult tracheostomy management. Crit Care Nurs Clin North Am 16(3): 413-430.

4. “2012 General Traffic Statistics.” (2013) Traffic Planning and Research. General Department of Traffic, Ministry of Interior, Kuwait.

5. Russell C (2005) Providing the nurse with a guide to tracheostomy care and management. Br J Nurs 14(8): 428-433.

6. Lewis $\mathrm{T}$, Oliver G (2005) Improving tracheostomy care for ward patients. Nurs Stand 19(19): 33-37.

7. Scotland NQ (2007) Caring for the Patient with a Tracheostomy, Best Practice Statement 20(4.3).

8. De leyn P, Bedert L, Delcroix M, Pieter Depuydt, Geert Lauwers, et al. (2007) Tracheotomy: clinical review and guidelines. Eur J Cardiothorac Surg 32(3): 412-421.

9. NHS Trust (2008) Tracheostomy care bundle forward patients' procedures. Dartford and Gravesham NHS Trust. UK.

10. Garrubba M \& Turner T (2009) Evidence-Based Practice Guidelines for Tracheostomy Patients: Evidence Review. Centre for Clinical Effectiveness, Southern Health.

11. Braz JR, Navarro LH, Takata IH, Nascimento júnior P (1999) Endotracheal tube cuff pressure: need for precise measurement. Sao Paulo Med J 117(6): 243-247.

12. Leigh JM, Maynard JP (1979) Pressure on the tracheal mucosa from cuffed tubes. Br Med J 1(6172): 1173-1174.

13. Mol DA, De villiers Gdu T, Claassen AJ, Joubert G (2004) Use and care of an endotracheal/tracheostomy tube cuff--are intensive care unit staff adequately informed? S Afr J Surg 42(1): 14-16.

14. Crimlisk JT, Horn MH, Wilson DJ, Marino B (1996) Artificial airways: a survey of cuffmanagement practices. Heart Lung 25: 225-235.

15. Casey D (2007) Tracheostomy. Open airways. Nurs Stand 3(22): 19-20.

16. Hooper M (1996) Nursing care of the patient with a tracheostomy. Nurs Stand 10(34): 40-43.

17. Carroll P (1994) Safe suctioning prn. RN 57(5): 32-36.

18. Allen D (1988) Making sense of suctioning. Nurs Times 84(10): 46-47.

19. Buglass E (1999) Tracheostomy care: tracheal suctioning and humidification. Br J Nurs 8(8): 500-504.

20. Day T, Farnell S, Haynes S, Wainwright S, Wilson barnett J (2002) Tracheal suctioning: an exploration of nurses' knowledge and competence in acute and high dependency ward areas. J Adv Nurs 39(1): 35-45

21. Dennis rouse MD, Davidson JE (2008) An evidence-based evaluation of tracheostomy care practices. Crit Care Nurs Q 31(2): 150-160.

22. White AC, Kher S, O'connor HH (2010) When to change a tracheostomy tube. Respir Care 55(8): 1069-1075.

23. De mestral C, Iqbal S, Fong N, Joanne LeBlanc, Paola Fata, et al. (2011) Impact of a specialized multidisciplinary tracheostomy team on tracheostomy care in critically ill patients. Can J Surg 54(3): 167-172.

\section{Your next submission with Juniper Publishers will reach you the below assets}

- Quality Editorial service

- Swift Peer Review

- Reprints availability

- E-prints Service

- Manuscript Podcast for convenient understanding

- Global attainment for your research

- Manuscript accessibility in different formats

( Pdf, E-pub, Full Text, Audio)

- Unceasing customer service

Track the below URL for one-step submission https://juniperpublishers.com/online-submission.php 